\title{
ОЦЕНКА ВЛИЯНИЯ РАЗЛИЧНЫХ СПОСОБОВ И АППАРАТОВ ЗАЩИТЫ ОТ ИМПУЛЬСНЫХ ПЕРЕНАПРЯЖЕНИЙ В ЭЛЕКТРИЧЕСКОЙ СЕТИ НАПРЯЖЕНИЕМ 6-10 КВ НЕФТЯНЫХ ПРОМЫСЛОВ
}

\section{Сидоров Сергей Владимирович',}

sidorovsv@tyuiu.ru

\author{
Сушков Валерий Валентинович, \\ sushkovvv@gray-nv.ru
}

\author{
Сухачев Илья Сергеевич, \\ suhachevis@tyuiu.ru \\ 1 Тюменский индустриальный университет,
Россия, 625000, г. Тюмень, ул. Володарского, 38.
${ }^{2}$ Нижневартовский государственный университет,
Россия, 628600, г. Нижневартовск, ул. Ленина, 56.
}

Актуальность. Одной из основных причин высокой аварийности и отключений в распределенных системах электроснабжения 6-10 кВ нефтяных промыслов являются перенапряжения вследствие грозовых воздействий. Подавляющее количество грозовых отключений в распределительных сетях 6-10 кB, связанных с перенапряжениями, обусловлено недостаточным уровнем импульсной прочности линейной изоляции, которое приводит к перекрытию изоляторов и в дальнейшем к обесточиванию нефтепромысловых потребителей. Для обеспечения требуемой грозоупорности распределенной системы электроснабжения нефтяных промыслов различными способами устанавливается защитное оборудование: ограничители перенапряжений, разрядники различных видов. При этом защитная аппаратура изменяет электрические характеристики распределительной сети, что влияет на характеристики переходных процессов при грозовых воздействиях. Следовательно, необходимо провести оценку влияния наиболее часто применяемых защитных аппаратов на перенапряжения в распределенной системе электроснабжения нефтяных промыслов при грозовых воздействиях.

Цель: оценить влияние защитного оборудования на уровни перенапряжений в электрических сетях 6(10) кВ нефтегазодобывающего предприятия при грозовых воздействиях.

Методы. Проведена оценка влияния защитной аппаратуры на уровни перенапряжений путем анализа переходного процесса и частотных характеристик для участка системы электроснабжения на грозовое воздействие с использованием алгоритмов пакета Linear Analysis Tools в MATLAB Simulink.

Результаты. Установлена зависимость уровня перенапряжений от вида защитных аппаратов. Получены частотные и временны'е характеристики входных перенапряжений потребителей, которые необходимо знать при выборе защитной аппаратуры. Определена зависимость резонансных частот от установленных искровых разрядников. Разработана в среде MATLAB Simulink cxeмa имитационной модели типового участка распределенной системы электроснабжения нефтегазодобывающего предприятия Западной Сибири, включая модели ограничителя перенапряжений, разрядника и грозового импульса. Предложены мероприятия по защите нефтепромысловых потребителей от импульсных перенапряжений.

\section{Ключевые слова:}

Нефтяной промысел, воздушная линия электропередачи, нелинейный ограничитель перенапряжения, разрядник, импульсные перенапряжения, параметры перенапряжений, имитационное моделирование, частотный анализ, переходные процессы.

\section{Введение}

В настоящее время в распределенной системе электроснабжения нефтегазодобывающих предприятий Западной Сибири высокая аварийность, достигающая 40 \% от общего числа отключений, обусловлена воздействием на электрооборудование импульсных, в частности грозовых, перенапряжений $[1,2]$.

В нефтепромысловых электрических сетях напряжением 6(10) кВ для повышения грозоупорности устанавливают нелинейные ограничители перенапряжений $(\mathrm{OПH)} \mathrm{и} \mathrm{разрядники} \mathrm{в} \mathrm{местах,} \mathrm{pe-}$ комендуемых нормативными документами. Подавляющее количество грозовых воздействий в распределительных сетях напряжением 6(10) кВ приходится на воздушную линию электропередачи (ЛЭП), при этом к самому тяжелому случаю относится прямой удар молнии в провод [3].
Для снижения уровней грозовых перенапряжений в большинстве случаев разрядники устанавливают на опорах ЛЭП, а ОПН - на подходах трансформаторных подстанций (ТП) $35 / 6(10)$ и $6(10) / 0,4$ кВ и в их распределительных устройствах [4-6]. Отказы электрооборудования, возникающие при грозовых перенапряжениях, приводят к перекрытию и повреждению изоляции электроустановок и простою технологического оборудования $[1,2,7]$, поэтому задача оценки влияния различных способов и аппаратов защиты на величину импульсных перенапряжений в электрической сети актуальна. Научно-практический интерес представляет выбор количества и места установки ОПН и разрядников в электрических сетях напряжением 6(10) кВ нефтегазодобывающих предприятий [8-13]. 


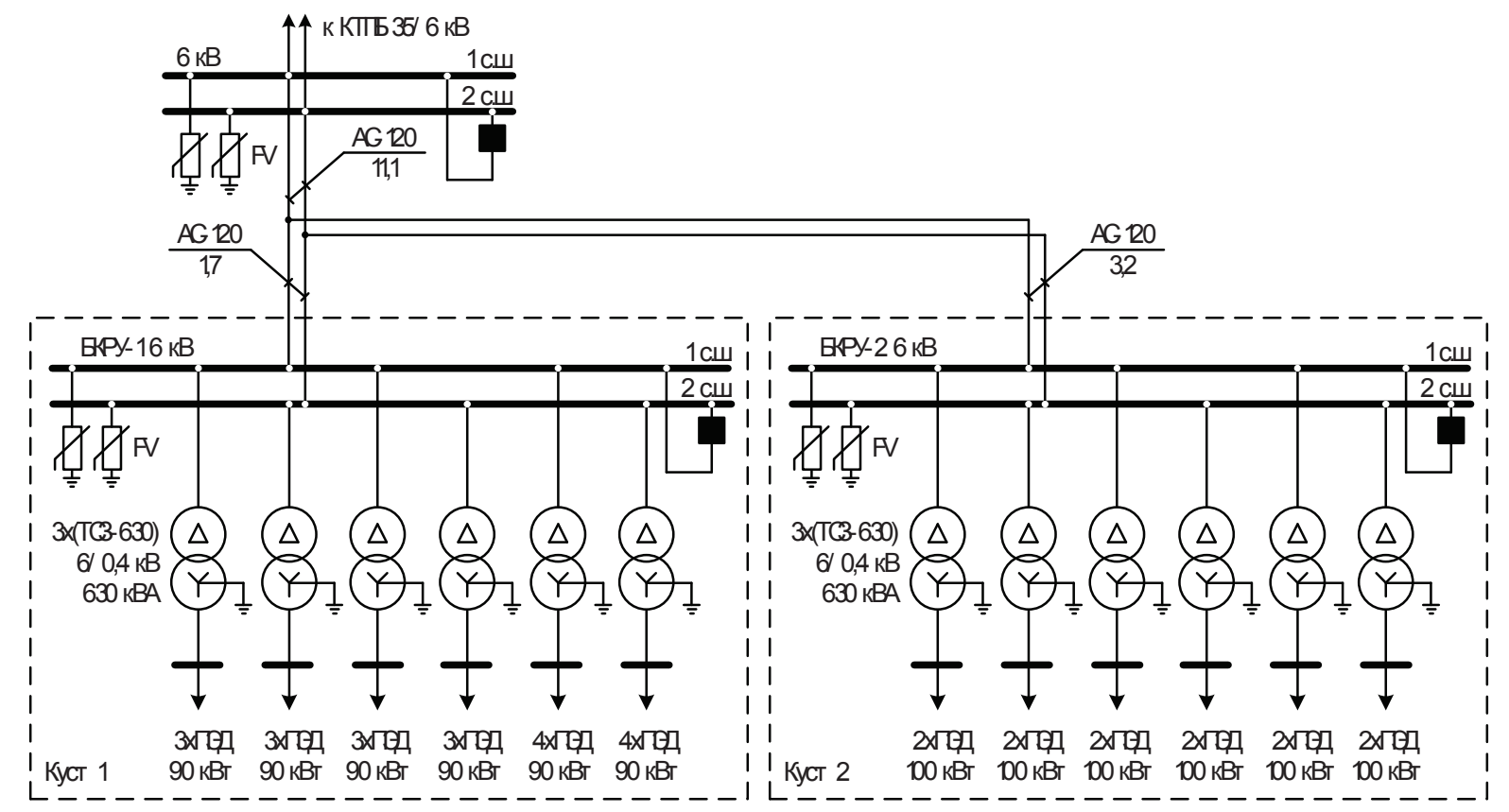

Рис. 1. Приниипиальная схема участка распределительной сети электроснабжения кустов нефтедобывающих скважин

Fig. 1. Schematic diagram of oil producing wells power distribution network section

\section{Объект и методы исследования}

В качестве объекта исследования принят участок распределительной сети с изолированной нейтралью напряжением 6 кВ нефтяного месторождения Западной Сибири. На рис. 1 приведена схема электроснабжения по двум секциям шин 6 кВ двух кустов нефтедобывающих скважин, получающих питание от блочных комплектных распределительных устройств БКРУ-1, двух трансформаторных подстанций $6 / 0,4$ кВ, подключенных воздушными линиями электропередачи к блочной комплектной трансформаторной подстанции КТПБ $35 / 6$ кВ. Нелинейные ограничители перенапряжений установлены на шинах 6 кВ. Длинноискровые разрядники установлены на опорах типа ПС10П-27М воздушной линии электропередачи.

Согласно принципиальной схеме электроснабжения с целью определения перенапряжений вдоль воздушной линии электропередачи вследствие воздействия грозового импульса разработана в программной среде MATLAB Simulink имитационная модель типового участка распределительной сети электроснабжения кустов нефтедобывающих скважин предприятия Западной Сибири, схема которой приведена на рис. 2.

При разработке имитационной модели приняты следующие допущения:

1. Секционные выключатели БКРУ 1 и 2 отключены, секции шин 6 кВ работают независимо, и питание осуществляется по одному вводу 6 кВ КТПБ $35 / 6$ кВ.

2. Параметры трехфазной симметричной нагрузки трансформаторов ТС3-630 6/0,4 кВ приведены к напряжению распределительной сети электроснабжения напряжением 6 кВ $[14,15]$.
3. Параметры воздушных линий электропередачи напряжением 6 кВ - тип опоры, марка провода, величина провиса провода - одинаковы по всей длине участка.

Модель характеризуется следующими особенностями:

1. ОПН и искровые разрядники моделируются нелинейными резисторами с соответствующими вольтамперными характеристиками [16].

2. В нормальном рабочем режиме разрядник моделируется емкостью на землю, в режиме пробоя - переходным сопротивлением.

3. При построении частотных характеристик емкость разрядников учитывается соответствующим пересчетом емкости на землю воздушной линии.

Имитационная модель позволяет рассчитать временные и частотные характеристики импульсных перенапряжений и токов в произвольных точках воздействия грозового импульса на распределительную сеть электроснабжения напряжением 6 кВ. На рис. 2 воздействие грозового импульса приходится в точку распределительной сети, отстоящую на расстояния $\mathrm{X}$ и Ү от начала отходящей линии до БКРУ-1 соответственно. Каждый участок распределительной сети электроснабжения представлен имитационной моделью трехфазной линии с распределёнными параметрами.

Согласно ГОСТ Р МЭК 62305-1-2010 и СО 153-34.21.122-2003, разработана имитационная модель грозового импульса, схема которой приведена на рис. 3.

Параметры имитационной модели участка распределительной сети электроснабжения кустов нефтедобывающих скважин приведены в таблице. 


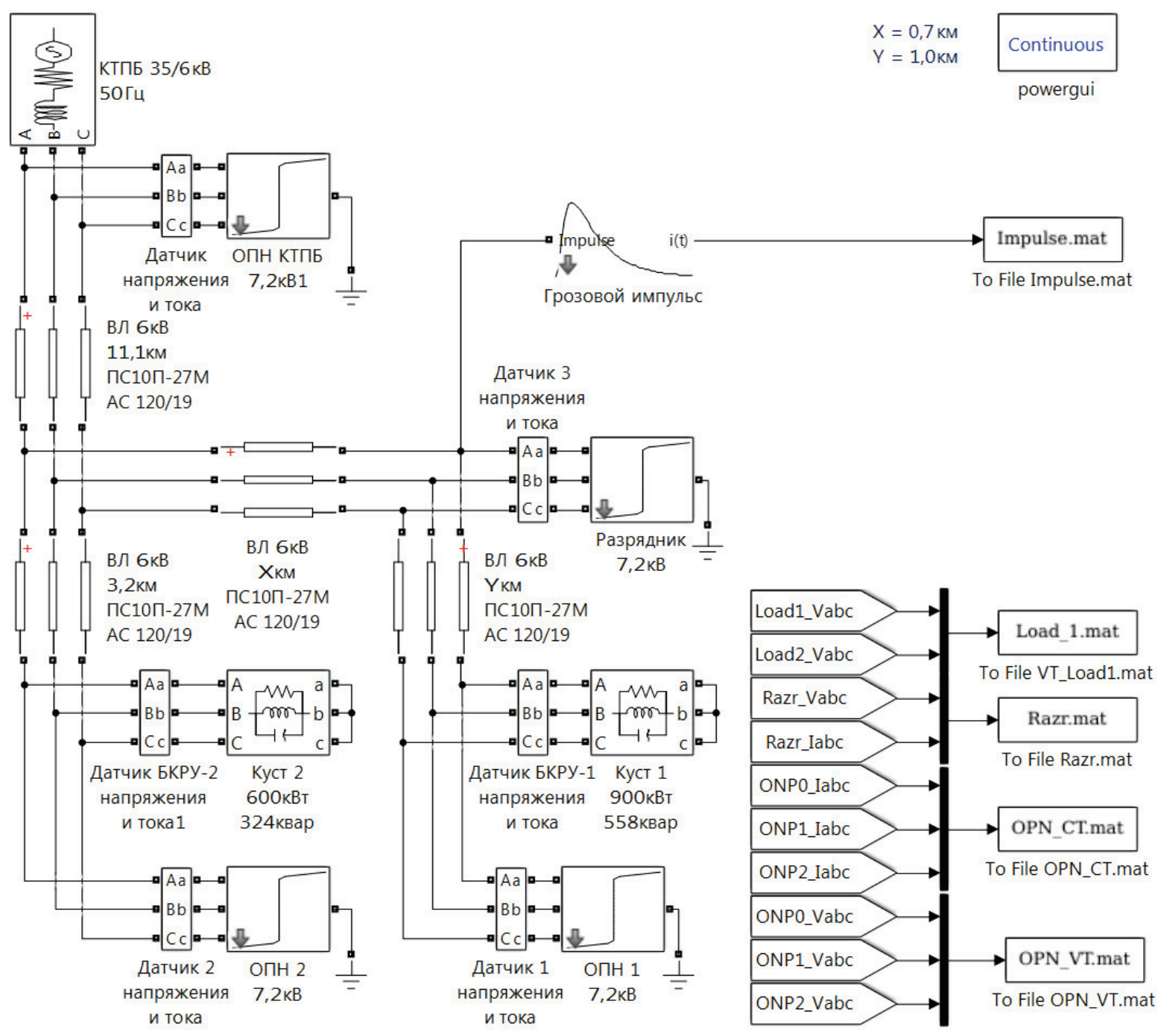

Pис. 2. Схема имитаиионной модели участка распределительной сети электроснабжения кустов нефтедобывающих скважин

Fig. 2. Simulation model of oil producing wells power distribution network section

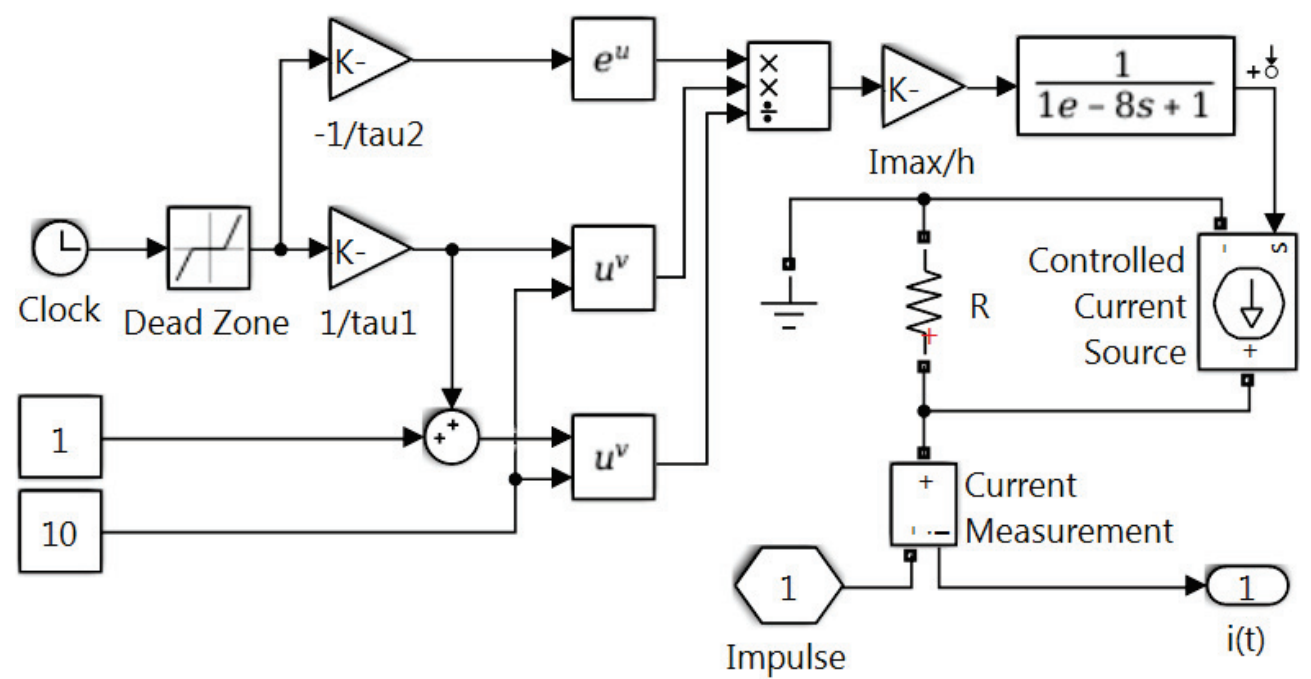

Pис. 3. Схема имитационной модели грозового импульса

Fig. 3. Simulation model of lightning impulse 
таблица. Параметры имитационной модели участка распре делительной сети электроснабжения кустов нефте добывающих скважин

Table. $\quad$ Parameters of simulation model of oil producing wells power distribution network section

\begin{tabular}{|c|c|c|}
\hline $\begin{array}{l}\text { Наименование блока } \\
\text { Block Name }\end{array}$ & $\begin{array}{l}\text { Параметры } \\
\text { Parameters }\end{array}$ & $\begin{array}{c}\text { Значения } \\
\text { Values }\end{array}$ \\
\hline \multirow{4}{*}{$\begin{array}{l}\text { Источник питания } \\
\text { ИП } \\
\text { Three-Phase Source }\end{array}$} & $\begin{array}{l}\text { Линейное напряжение, } \mathrm{kB} \\
\text { Phase-to-phase voltage, kV }\end{array}$ & 6,3 \\
\hline & $\begin{array}{l}\text { Частота, Гц } \\
\text { Frequency, } \mathrm{Hz}\end{array}$ & 50 \\
\hline & $\begin{array}{l}\text { Активное сопротивление, Ом } \\
\text { Source resistance, Ohms }\end{array}$ & 0,8929 \\
\hline & $\begin{array}{l}\text { Индуктивность, мГн } \\
\text { Source inductance, } \mathrm{mH}\end{array}$ & 16,58 \\
\hline \multirow{3}{*}{$\begin{array}{l}\text { Воздушная линия } \\
6 \text { кB } \\
\text { Three-Phase Line } 6 \mathrm{kV}\end{array}$} & $\begin{array}{l}\text { Сопротивления прямой и нулевой } \\
\text { последовательностей фаз, Ом/км } \\
\text { Positive- and zero-sequence } \\
\text { resistances, Ohms/km }\end{array}$ & $\begin{array}{l}0,24929 \\
0,39534\end{array}$ \\
\hline & $\begin{array}{l}\text { Индуктивности прямой и нулевой } \\
\text { последовательностей фаз, мГн } / \text { км } \\
\text { Positive- and zero-sequence } \\
\text { inductances, } \mathrm{mH} / \mathrm{km}\end{array}$ & $\begin{array}{l}1,2015 \\
5,0511\end{array}$ \\
\hline & $\begin{array}{l}\text { Емкости прямой и нулевой после- } \\
\text { довательностей фаз, нФ/км } \\
\text { Positive- and zero-sequence } \\
\text { resistances, } \mathrm{nF} / \mathrm{km}\end{array}$ & $\begin{array}{l}9,6699 \\
4,7011\end{array}$ \\
\hline \multirow{2}{*}{$\begin{array}{l}\text { Потребители 1, } 2 \\
\text { Load 1, } 2\end{array}$} & $\begin{array}{l}\text { Активное сопротивление, Ом } \\
\text { Source resistance, Ohms }\end{array}$ & 400360 \\
\hline & \begin{tabular}{|l} 
Индуктивность, Гн \\
Source inductance, Н
\end{tabular} & $\begin{array}{l}2,0545 \\
2,1231\end{array}$ \\
\hline
\end{tabular}

Порядок расчета грозовых перенапряжений на имитационной модели заключается в следующем:

1. Параметры грозового воздействия приняты согласно ГОСТ Р МЭК 62305-1-2010 [17] и СО 153-34.21.122-2003 [18] и заносятся в блок Грозовой илиульс i $(t)$.

2. Вычисляются параметры воздушных линий и заносятся в блоки $В Л ~ 6 \kappa B$ : основная частота, погонные сопротивления, индуктивности, емкости прямой и нулевой последовательностей, длина воздушной линии (или участка ВЛ) в зависимости от типа опоры, марки провода, провиса провода, удельного сопротивления грунта.

3. Принимаются параметры ОПН согласно паспортным данным: коэффициенты аппроксимации вольтамперной характеристики $I(U)=I_{p r}\left(U / U_{p r}\right)^{\alpha}$, где $U_{p r}$ - защитное напряжение, $I_{p r}$ - опорный ток.

a)

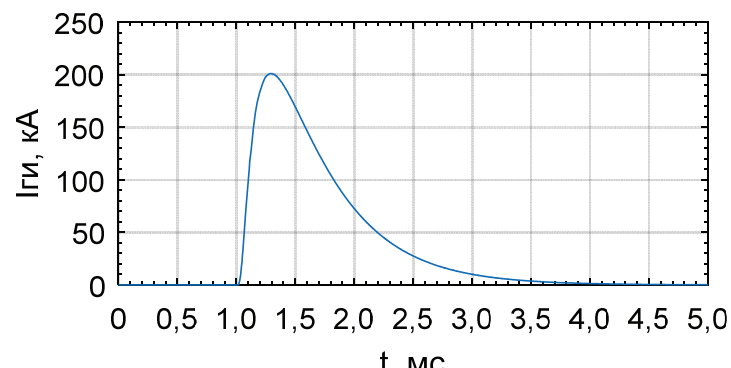

4. Принимаются параметры искровых разрядников: емкость искрового промежутка и коэффициенты аппроксимации вольтамперной характеристики.

5. Указываются параметры источника питания ИП: режим работы нейтрали, номинальные величины напряжения и частоты, величины внутреннего сопротивления и индуктивности.

6. Вычисляются параметры трехфазной симметричной нагрузки трансформаторов ТСЗ-630 6/0,4 кВ, приведенные к напряжению воздушной линии $6 \mathrm{kB}$ : величины активного сопротивления и индуктивности по номинальным значениям напряжения, частоты питающей сети, активной мощности нагрузки и коэффициента мощности.

7. Посредством Linear Analysis Tools производится построение амплитудно- и фазочастотных характеристик (Bode Diagram) импульсных перенапряжений исследуемого участка воздушной линии электропередачи распределительной сети, ограниченного входной Input Perturbation и выходной Output Measurements точками модели.

8. Вычисленные временны́ е функции напряжений сохраняются модулем вывода информации в файл в виде массива данных.

Результаты моделирования приведены на рис. 4-7.

Изначально модель работает в нормальном установившемся режиме. Исследуем уровни перенапряжений на вводе БКРУ-1 6/0,4 кВ распределительной сети электроснабжения 6 кВ при возникновении грозового воздействия спустя 1 мс с начала моделирования. Осциллограмма максимально допустимого грозового импульса по I уровню защиты [18] приведена на рис. 4, a. В случае отсутствия нелинейных ограничителей перенапряжений и искровых разрядников осциллограмма линейных напряжений приведена на рис. $4, b$, амплитуда которых составляет $2,8 \mathrm{MB}$, что примерно в 200 раз превышает допустимое значение [19].

Согласно правилам устройств электроустановок, БКРУ комплектуется нелинейными ограничителями перенапряжений как по высокой стороне, так и по низкой. В этом случае уровень перена-

b)

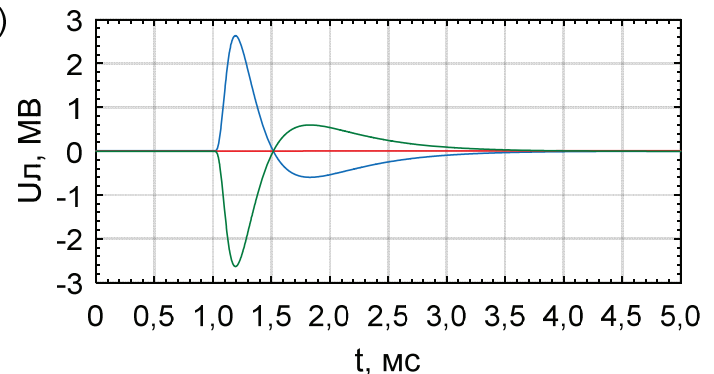

Pис. 4. Осииллогралмы: а) грозового илпульса; b) линейных напряжений на вводе БКРУ-1 6/0,4 кВ при отсутствии защитного оборудования

Fig. 4. Oscillograms of: a) lightning impulse; b) phase-to-phase voltage at the input block switchgear № $16 / 0,4 \mathrm{kV}$ without protection devices 
a)

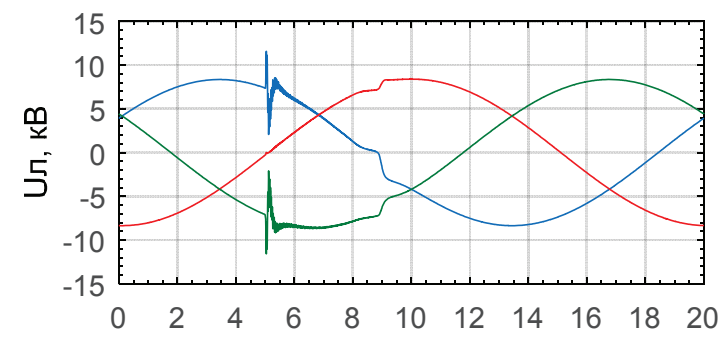

b)

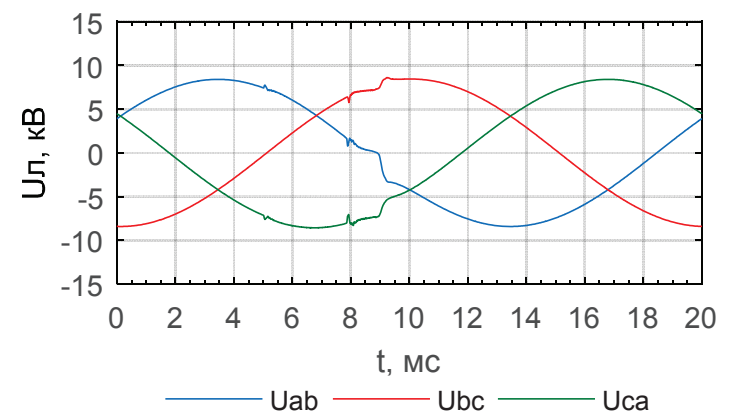

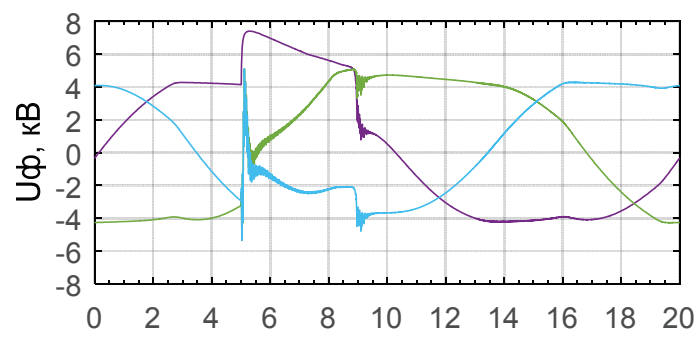

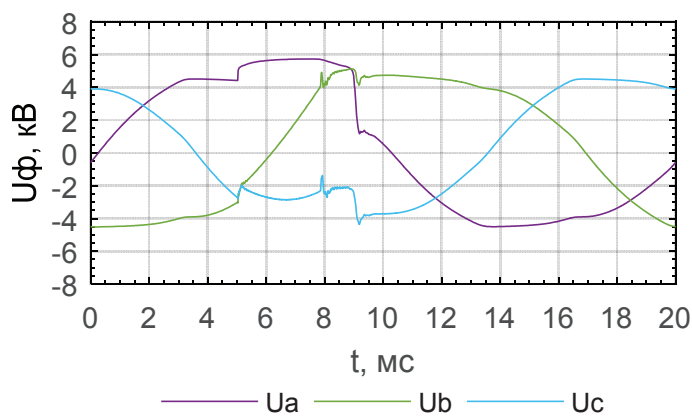

Рис. 5. Осииллогралмы линейных напряжений на вводе БКРУ-1 6/0,4 кВ и фазных напряжений ОПН-1: а) при отсутствии разрядников вдоль ЛЭП $6 \kappa$; $b$ ) при установке разрядников вдоль ЛЭП $6 \kappa$ К

Fig. 5. Phase-to-phase voltage oscillograms at the input block switchgear № $16 / 0,4 \mathrm{kV}$ and phase-to-ground voltage non-linear surge arrester: a) without arresters on the overhead power line $6 \mathrm{kV} ; \mathrm{b}$ ) with arresters on the overhead power line $6 \mathrm{kV}$

a)

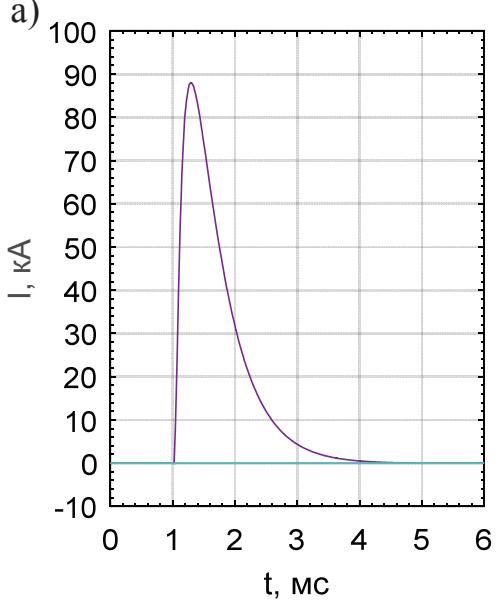

b)

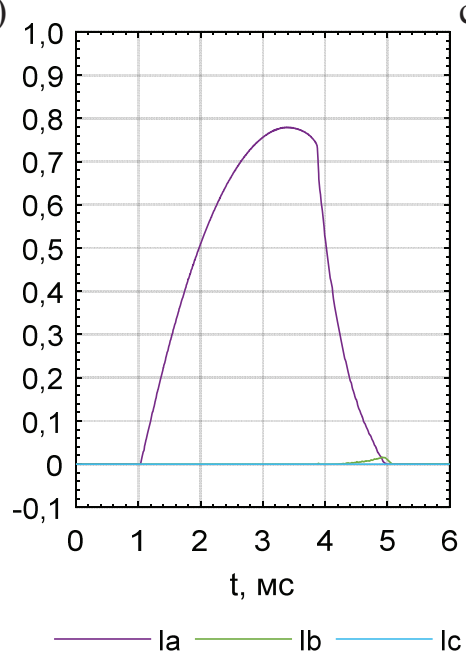

c)

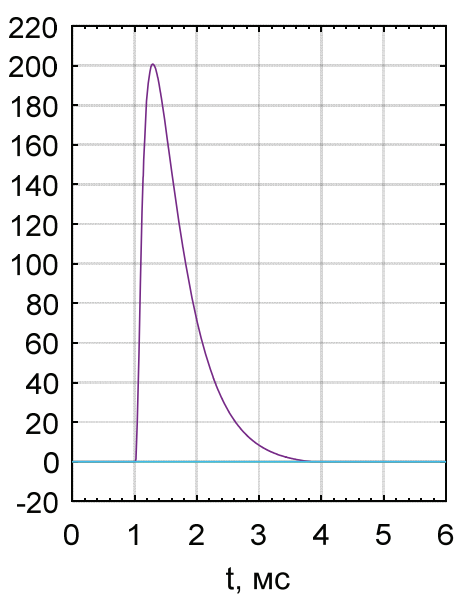

Pис. 6. Осииллограмлы фазных токов ОПн без разрядников (а), с разрядниками (b); осциллограллы фазных токов разрядника вблизи места грозового воздействия (c)

Fig. 6. Phase-to-ground current oscillograms at the non-linear surge arrester without arresters (a), with arresters (b); phase-to-ground current oscillograms at the arrester near the place of lightning effects $(c)$

пряжения на вводе БКРУ-1 6/0,4 кВ снижается до 12,5 кВ, что в 1,5 раза превышает рабочие значения. Результаты моделирования приведены на рис. 5, a. На рис. 5, $b$ получены осциллограммы при установке разрядников вдоль ЛЭП 6 кВ, при этом уровень перенапряжения не превышает $5 \%$ рабочего напряжения, на 2 кВ снизилось перенапряжение на ОПН-1.

Осциллограммы фазных токов ОПН при наличии и отсутствии разрядников приведены на рис. $6, a, b$, соответственно. Установка разрядни- ков снижает амплитуду разрядного тока в 112 раз и увеличивает длительность разряда в 1,3 раза, что сокращает тепловую нагрузку на ОПН и увеличивает срок его эксплуатации $[5,20]$. Осциллограмма фазных токов разрядника вблизи места грозового воздействия приведены на рис. $6, c$.

Для оценки влияния защитных аппаратов на спектральный состав перенапряжений построены частотные характеристики, полученные инструментом MATLAB Simulink Linear Analysis Tool на рис. 7. 


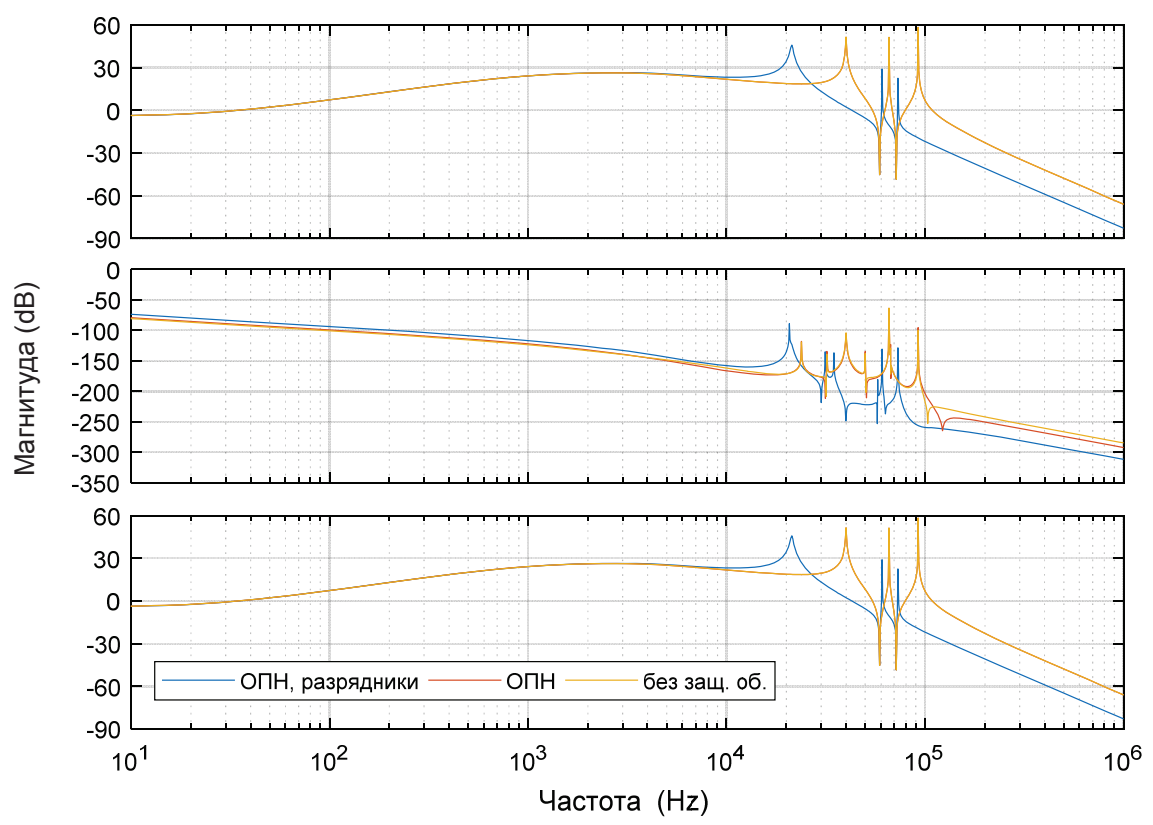

Pис. 7. Частотные характеристики импульсных перенапряжений на вводе БКРУ-1 6/0,4 кB- $U_{a b}^{(\S)}, U_{b c}^{(\dagger)} U_{c a}^{(\dagger)}$ соответственно

Fig. 7. Frequency characteristics of impulse overvoltages on the input block switchgear № $16 / 0,4 k V-U_{a b}^{\langle b}, U_{b c}^{\lfloor\uparrow}$, $U_{c a}^{\langle\uparrow}$ respectively

Полученные частотные характеристики $U^{\natural}$ позволяют по известному спектру импульсного воздействия $I_{\text {impulse }}(f)$ рассчитать величины перенапряжений $U(f)$ на конце исследуемой воздушной линии распределенной энергосистемы:

$$
U(f)=I_{\text {impulse }}(f) \cdot U^{\langle f\rangle} \text {. }
$$

Грозовое воздействие на линейный провод фазы А ЛЭП вызывает перенапряжение между фазами $U_{a b}^{\bowtie}, U_{c a}^{\Uparrow}$ на вводе БКРУ-1.

При отсутствии разрядников наибольшие перенапряжения лежат в диапазоне частот $40-90$ кГц. В случае установки разрядников на опоры ЛЭП наибольшие перенапряжения смещаются в диапазон 21-71 кГц, что необходимо учитывать при выборе вида защитных аппаратов, их количества и места установки.

\section{Заключение}

1. Применение ОПН ограничивает напряжение на вводе БКРУ-1 6/0,4 кВ на уровне, в 1,5 раза превышающем рабочие значения. Установка разрядников на опорах ЛЭП и ОПН на трансформа-

\section{СПИСОК ЛИТЕРАТУРЫ}

1. Оценка остаточного ресурса изоляции погружного электродвигателя установок электрических центробежных насосов добычи нефти при воздействиях импульсных перенапряжений / В.В. Сушков, В.В. Тимошкин, И.С. Сухачев, С.В. Сидоров // Известия Томского политехнического университета. Инжиниринг георесурсов. - 2017. - Т. 328. - № 10. - С. 74-80.

2. Устройство регистрации, идентификации перенапряжений и оценки остаточного ресурса изоляции погружных электродвигателей: пат. 2655948 Российская Федерация № 2017109534; заявл. 21.03.2017; опубл. 30.05.2018, Бюл. № 16. - 8 с. торных подстанциях $35 / 6$ и $6 / 0,4$ кB снижает уровень перенапряжения до $5 \%$ рабочего напряжения, что подтверждает правильность рекомендаций, приведенных в нормативных документах при условии исправного технического состояния электроустановок. Так, повышение на 20 \% величины сопротивления заземления опор ЛЭП приводит к увеличению перенапряжения на линейной изоляции в три раза $[13,21-23]$.

2. Установка разрядников на ЛЭП приводит к смещению максимальных перенапряжений в область более низких частот, что чревато пробоем линейной изоляции ЛЭП.

3. Для того чтобы перенапряжения не достигали опасных значений в широком диапазоне частот грозового импульса, необходимо проводить расчет по определению количества, места установки разрядников и ОПН с учетом их влияния на амплитудно-частотную характеристику питающего напряжения потребителей.

Работа выполнена в рамках гранта Президента РФ для государственной поддержки молодых российских ученых (СП-829.2018.1).

3. Transient Voltage Measurements for Overhead Transmission Lines and Substations by Metal-Free and Contactless Integrated Electro-Optic Field Sensors / H. Wang, C. Zhuang, R. Zeng, S. Xie, J. He // IEEE Transactions on Industrial Electronics. 2018. - V. 66. - № 1. - P. 571-579.

4. Ограничители перенапряжений для защиты изоляции электрооборудования и линий сетей среднего, высокого и сверхвысокого напряжения от грозовых и внутренних перенапряжений / Ф.Х. Халилов, В.Г. Гольдштейн, А.В. Колычев, В.П. Степанов, В.В. Титков. - М.: Энергоатомиздат, 2010. 264 c. 
5. Халилов Ф.Х., Евдокунин Г.А., Поляков В.С. Защита сетей 6-35 кВ от перенапряжений. - СПб.: Энергоатомиздат, 2002. $272 \mathrm{c}$.

6. Study of importance of line entrance arrester for a composite transmission circuit / P. Valsalal, S. Usa, K. Udayakumar, V. Sankaranarayanan // Proceedings of the IEEE Power Engineering Society Transmission and Distribution Conference. 2002. - V. 2. - № ASIA PACIFIC. - P. 694-698.

7. Карамов Д.Н., Наумов И.В., Пержабинский С.М. Математическое моделирование отказов элементов электрической сети $(10$ кВ) автономных энергетических систем с возобновляемой распределенной генерацией // Известия Томского политехнического университета. Инжиниринг георесурсов. - 2018. T. 329. - № 7. - C. 116-130.

8. Firouzjah K.G. Distribution network expansion based on the optimized protective distance of surge arresters // IEEE Transactions on Power Delivery. - 2018. - V. 33. - № 4. - P. 1735-1743.

9. Requirements of Arresters for Deeply Suppressing Switching Overvoltage in AC UHV Systems / J. Wu, J. Hu, P. Meng, J. He // Gaodianya Jishu/High Voltage Engineering. - 2017. - V. 43. № 12. - P. 4132-4138.

10. The power plant arrester configuration and modeling of insulation coordination / P. Chen, X. Fan, H. Wei, J. Zou, X. Xu, Y. He, B. Feng, Z. Wang, H. Liu // Proceedings 2017 Chinese Automation Congress, CAC 2017. - Jinan, China, 2017. - P. 6528-6533.

11. An integrated monitoring system and automatic data analysis to correlate lightning activity and faults on distribution networks / A.E. Lazzaretti, S.L. França Santos, K.K. Küster, L.F. Ribeiro Barrozo Toledo, M.A. Ravaglio, A. Piantini, C.L. da Silva Pinto // Electric Power Systems Research. - 2017. - V. 153. - P. 66-72.

12. Study on lightning overvoltage protection methods for UHV GIS substation with different lightning / L. Wang, J. Xu, S. Hao, H. Chen, S. Ma, W. Zhai // ICEPE-ST $2017-4^{\text {th }}$ International Conference on Electric Power Equipment- Switching Technology. - Zhangzhou, China, 2017. - P. 808-812.

13. Shariatinasab R., Gholinezhad J. The effect of grounding system modeling on lightning-related studies of transmission lines // Journal of Applied Research and Technology. - 2017. - V. 15. № 6. - P. 545-554.

14. Букреев В.Г., Шандарова Е.Б., Рулевский В.М. Многомерная модель системы электропитания погружного технологическо- го оборудования // Известия Томского политехнического университета. Инжиниринг георесурсов. - 2018. - Т. 329. - № 4. C. $119-131$.

15. Боловин Е.В., Глазырин А.С. Метод идентификации параметров погружных асинхронных электродвигателей установок электроприводных центробежных насосов для добычи нефти // Известия Томского политехнического университета. Инжиниринг георесурсов. - 2017. - Т. 328. - № 1. - С. 123-131.

16. Bedoui S., Bayadi A. Probabilistic evaluation of the substation performance under incoming lightning surges // Electric Power Systems Research. - 2018. - V. 162. - P. 125-133.

17. ГОСТ Р МЭК 62305-1-2010. Менеджмент риска. Защита от молнии. Ч. 1. Общие принципы. - М.: Стандартинформ, 2011. $-45 \mathrm{c}$.

18. Инструкция по устройству молниезащиты зданий, сооружений и промышленных коммуникаций (СО 153-34.21. 122-2003). - СПб.: ДЕАН, 2005. - 64 с.

19. Кадомская К.П., Лавров Ю.А., Рейхердт А.А. Перенапряжения в электрических сетях различного назначения и защита от них. - Новосибирск: Изд-во НГТУ, 2004. - 320 с.

20. Кадомская К.П., Рейхердт А.А. Моделирование волны тока молнии при расчетах грозоупорности электрических сетей // Электричество. - 2006. - № 11. - С. 17-23.

21. Сушков В.В., Сухачев И.С., Сидоров С.В. Оценка и способы повышения остаточного ресурса изоляции погружных электродвигателей электротехнического комплекса добычи нефти при воздействиях импульсных перенапряжений // Электрооборудование: эксплуатация и ремонт. - 2017. - № 12. - С. 50-55.

22. Alipio R., Duarte M.H.R., Lima A.C.S. Influence of grounding representation on the lightning performance of line surge arresters. P. I: Impact on the developed overvoltages // SBSE 2018 $7^{\text {th }}$ Brazilian Electrical Systems Symposium. - Rio de Janeiro, Brazil, 2018. - P. 1-6.

23. Влияние внутрискважинного компенсатора на падение напряжения в элементах электротехнического комплекса добывающей скважины / В.А. Копырин, О.В. Смирнов, А.Л. Портнягин, Р.Н. Хамитов // Известия Томского политехнического университета. Инжиниринг георесурсов. - 2018. - Т. 329. № 9. - C. 117-124.

Поступила 05.10.2018 г.

\section{Информация об авторах}

Cuдоров C.B., старший преподаватель кафедры электроэнергетики Тюменского индустриального университета.

Сушков В.B., доктор технических наук, профессор кафедры энергетики Нижневартовского государственного университета.

Сухачев И.С., старший преподаватель кафедры электроэнергетики Тюменского индустриального университета. 


\title{
ESTIMATION OF THE EFFECT OF VARIOUS METHODS AND DEVICES OF IMPULSE OVERVOLTAGE PROTECTION IN THE OIL FIELD ELECTRIC NETWORK 6-10 kV
}

\author{
Sergey V. Sidorov',
}

sidorovsv@tyuiu.ru

Valery V. Sushkov²,

sushkovvv@gray-nv.ru

\author{
Ilya S. Sukhachev', \\ suhachevis@tyuiu.ru \\ 1 Tyumen Industrial University, \\ 38, Volodarsky Street, Tyumen, 625000, Russia. \\ 2 Nizhnevartovsk State University, \\ 56, Lenin Street, Nizhnevartovsk, 628600, Russia.
}

\begin{abstract}
Relevance. One of the main causes of high accident rate and outages in distributed power supply systems of 6-10 kV oil fields are overvoltages due to lightning effects. The overwhelming number of lightning outages in distribution networks of 6-10 kV, associated with overvoltages, is caused by insufficient level of impulse durability of linear insulation, which leads to the insulator overlap and later to deenergizing of oilfield consumers. To ensure the required lightning resistance of the distributed power supply system for oil fields, various methods are used to install protection devices: non-linear surge arresters, arresters of various types. In this case, the protection devices change the electrical characteristics of the distribution network, which affects the characteristics of transitional processing lightning effects. Therefore, it is necessary to estimate the effect of the most frequently used protective devices on overvoltage in a distributed power supply system for oil fields during lightning effects.

The main aim of the research is to estimate the impact of protection devices on overvoltage levels in electric networks of $6(10) \mathrm{kV}$ of an oil and gas extraction enterprise during lightning effects.

Methods. The authors have estimated the influence of protection devices on overvoltage levels by analyzing the transitional process and frequency characteristics for a part of the power supply system on a lightning effect using the algorithms of the Linear Analysis Tools in MATLAB Simulink.

Results. The authors determined the dependence of overvoltage level on the type of protective devices and obtained the frequency and time characteristics of the input overvoltage of the consumers, which should be known when choosing protection devices. The dependence of the resonance frequencies on the installed spark gaps is determined. The authors developed in the MATLAB Simulink the simulation model of a typical part of a distributed power supply system of an oil and gas extraction enterprise in Western Siberia, including a non-linear surge arrester, arrester and lightning impulse. The activities to protect oil fields consumers from impulse overvoltages were proposed.
\end{abstract}

\section{Key words:}

Oil field, overhead power line, non-linear surge arrester, arrester, impulse overvoltage, overvoltage parameters, simulation, frequency analysis, transitional processes.

The research was carried out within the Grant of the President of the RF for state support of young Russian scolars (SP-829.2018.1).

\section{REFERENCES}

1. Sushkov V.V., Timoshkin V.V., Sukhachev I.S., Sidorov S.V. Evaluation of submersible electric motor insulation residual resource in oil production electric centrifugal pumps under the influence of impulse overvoltages. Bulletin of the Tomsk Polytechnic University. Geo Assets Engineering, 2017, vol. 328, no. 10 , pp. 74-80. In Rus.

2. Sushkov V.V., Sukhachev I.S. Ustroystvo registratsii, identifikatsiya perenapryazheniy i otsenki ostatochnogo resursa izolyatsii pogruzhnykh elektrodvigateley [Registration device, identification of overvoltages and evaluation of the residual life of insulation of submersible motors]. Patent RF, no. 2655948, 2018.

3. Wang H., Zhuang C., Zeng R., Xie S., He J. Transient Voltage Measurements for Overhead Transmission Lines and Substations by Metal-Free and Contactless Integrated Electro-0ptic Field Sensors. IEEE Transactions on Industrial Electronics, 2018, vol. 66, no. 1 , pp. 571-579.
4. Khalilov F.Kh., Goldshteyn V.G., Kolychev A.V., Stepanov V.P., Titkov V.V. Ogranichiteli perenapryazheniy dlya zashchity izolyatsii elektrooborudovaniya $i$ liniy setey srednego, vysokogo $i$ sverkhvysokogo napryazheniya ot grozovykh $i$ vnutrennikh perenapryazheniy [0vervoltage limiters for protection of insulation of electrical equipment and medium, high and extra-high voltage network lines from lightning and internal overvoltages]. Moscow, Energoatomizdat Publ., 2010. 264 p.

5. Khalilov F.Kh., Evdokunin G.A., Polyakov V.S. Zashchita setey $6-35 \mathrm{kV}$ ot perenapryazheniy [Protection of $6-35 \mathrm{kV}$ networks from overvoltage]. St. Petersburg Energoatomizdat Publ., 2002. $272 \mathrm{p}$.

6. Valsalal P., Usa S., Udayakumar K., Sankaranarayanan V. Study of importance of line entrance arrester for a composite transmission circuit. Proceedings of the IEEE Power Engineering Society Transmission and Distribution Conference, 2002, vol. 2, no. ASIA PACIFIC, pp. 694-698. 
7. Karamov D.N., Naumov I.V., Perzhabinsky S.M. Mathematical modelling of failures of electrical grid $(10 \mathrm{kV})$ of autonomous energy systems with renewable distributed generation. Bulletin of the Tomsk Polytechnic University. Geo Assets Engineering, 2018, vol. 329, no. 7, pp. 116-130. In Rus.

8. Firouzjah K.G. Distribution network expansion based on the optimized protective distance of surge arresters. IEEE Transactions on Power Delivery, 2018, vol. 33, no. 4, pp. 1735-1743.

9. Wu J., Hu J., Meng P., He J. Requirements of Arresters for Deeply Suppressing Switching 0vervoltage in AC UHV Systems. Gaodianya Jishu/High Voltage Engineering, 2017, vol. 43, no. 12, pp. 4132-4138.

10. Chen P., Fan X., Wei H., Zou J., Xu X., He Y., Feng B., Wang Z., Liu H. The power plant arrester configuration and modeling of insulation coordination. Proceedings 2017 Chinese Automation Congress, CAC 2017. Jinan, China, 201, pp. 6528-6533.

11. Lazzaretti A.E., França Santos S.L., Küster K.K., Ribeiro Barrozo Toledo L.F., Ravaglio M.A., Piantini A., Da Silva Pinto C.L. An integrated monitoring system and automatic data analysis to correlate lightning activity and faults on distribution networks. Electric Power Systems Research, 2017, vol. 153, pp. 66-72.

12. Wang L., Xu J., Hao S., Chen H., Ma S., Zhai W. Study on lightning overvoltage protection methods for UHV GIS substation with different lightning. ICEPE-ST $2017-4^{\text {th }}$ International Conference on Electric Power Equipment - Switching Technology. Zhangzhou, China, 2017, pp. 808-812.

13. Shariatinasab R., Gholinezhad J. The effect of grounding system modeling on lightning-related studies of transmission lines. Journal of Applied Research and Technology, 2017, vol. 15, no. 6, pp. 545-554.

14. Bukreev V.G., Shandarova E.B., Rulevskiy V.M. Power supply system model of remote processing equipment. Bulletin of the Tomsk Polytechnic University. Geo Assets Engineering, 2018, vol. 329 , no. 4, pp. 119-131. In Rus.

15. Bolovin E.V., Glazyrin A.S. Method for identifying parameters of submersible induction motors of electrical submersible pump units for oil production. Bulletin of the Tomsk Polytechnic University. Geo Assets Engineering, 2017, vol. 328, no. 1, pp. 123-131. In Rus.
16. Bedoui S., Bayadi A. Probabilistic evaluation of the substation performance under incoming lightning surges. Electric Power Systems Research, 2018, vol. 162, pp. 125-133.

17. GOST 62305-1:2010. Menedzhment riska. Zashchita ot molnii. Ch.1.Obshchie printsipy [State Standard 62305-1:2010. Risk management. Protection against lightning. P. 1. General principles]. Moscow, Standartinform Publ., 2011. 45 p.

18. CO 153-34.21.122-2003. Instruktsiya po ustroystou molniezashchity zdaniy, sooruzheniy i promyshlennykh kommunikatsiy [Instructions for lightning protection of buildings, structures and industrial communications]. St. Petersburg, DEAN Publ., $2005.64 \mathrm{p}$.

19. Kadomskaya K.P., Lavrov Yu.A., Reykherdt A.A. Perenapryazheniya $v$ elektricheskikh setyakh razlichnogo naznacheniya $i$ zashchita ot nikh [0vervoltage in electrical networks for various purposes and protection against them]. Novosibirsk, NSTU Publ., $2004.320 \mathrm{p}$.

20. Kadomskaya K.P., Reykherdt A.A. Simulation of a lightning current wave in calculations of the lightning resistance of electrical networks. Elektrichestvo, 2006, no 11. pp. 17-23. In Rus.

21. Sushkov V.V., Sukhachev I.S., Sidorov S.V. Evaluation and methods for increasing the residual insulation resource of submersible electric motors of an electrical engineering complex for oil production under the effects of impulse overvoltages. Electrical equipment: operation and repair, 2017, no 12, pp. 50-55. In Rus.

22. Alipio R., Duarte M.H.R., Lima A.C.S. Influence of grounding representation on the lightning performance of line surge arresters. Part I: Impact on the developed overvoltages. SBSE 2018 $7^{\text {th }}$ Brazilian Electrical Systems Symposium. Rio de Janeiro, Brazil, 2018. pp. 1-6.

23. Kopyrin V.A., Smirnov O.V., Portnyagin A.L., Khamitov R.N. Influence of downhole compensator on voltage drop in elements of a production well electrical system. Bulletin of the Tomsk Polytechnic University. Geo Assets Engineering, 2018, vol. 329, no. 9, pp. 117-124. In Rus.

\section{Information about the authors}

Sergey V. Sidorov, teaching assistant, Tyumen Industrial University.

Valery V. Sushkov, Dr. Sc., professor, Nizhnevartovsk State University.

Ilya S. Sukhachev, teaching assistant, Tyumen Industrial University. 